NASA Technical Memorandum 103213

\title{
Estimation of Minority Carrier Diffusion Lengths in InP/GaAs Solar Cells
}

R.K. Jain and D.J. Flood

Lewis Research Center

Cleveland, Ohio

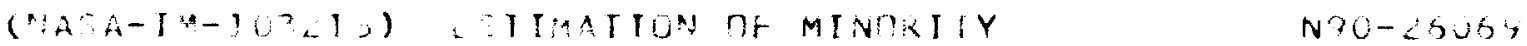

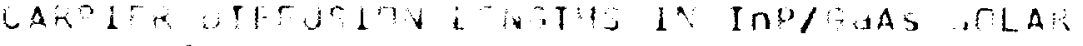

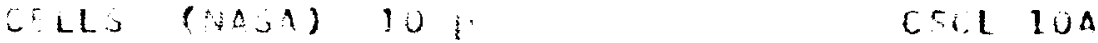

$$
\begin{aligned}
& \begin{array}{l}
\text { Unclis } \\
3120 \text { 0?4519. }
\end{array}
\end{aligned}
$$

\section{Prepared for the}

Second International Conference on Indium Phosphide and Related Materials cosponsored by the IEEE Lasers and Electro-Optics Society and

the IEEE Electron Device Society

Denver, Colorado, April 23-25, 1990 



\title{
Estimation of Minority Carrier Diffusion Lengths in InP/GaAs Solar Cells
}

\author{
R. K. Jain* and D. J. Flood \\ NASA Lewis Research Center \\ 21000 Brookpark Road, Cleveland, OH 44135
}

\begin{abstract}
Minority carrier diffusion length is one of the most important parameters affecting the solar cell performance. In this paper an attempt is made to estimate the minority carrier diffusion lengths in the emitter and base of InP/GaAs heteroepitaxial solar cells. The PC-10 computer model has been used to simulate the experimental cell results measured at NASA Lewis under AMO spectrum at $25^{\circ} \mathrm{C}$. A $16 \mathrm{~nm}$ hole diffusion length in the emitter and a $0.42 \mu \mathrm{m}$ electron diffusion length in the base gave very good agreement with the I-V curve. The effect of varying minority carrier diffusion lengths on cell short circuit current, open circuit voltage and efficiency has been studied. It is also observed that the front surface recombination velocity has very little influence on the cell performance. The poor output of heteroepitaxial cells is caused primarily by the large number of dislocations generated at the interfaces that propagate through the bulk indium phosphide layers. Cell efficiency as a function of dislocation density has been calculated and the effect of improved emitter bulk properties on cell efficiency is presented. It is found that cells with over $16 \%$ AMO efficiencies should be possible provided the dislocation density is below $10^{6} \mathrm{~cm}^{-2}$.
\end{abstract}

Introduction Minority carrier diffusion length is one of the most important parameters affecting the solar cell performance. Unlike silicon or gallium arsenide, indium phosphide is still not well understood, and several physical parameters must yet be measured correctly. In this paper an attempt is made to estimate the minority carrier diffusion lengths in the emitter and base of InP solar cells grown by MOCVD on GaAs wafers.

Recently indium phosphide has emerged as a promising material for space power applications due to its superb radiation resistance $[1,2]$ and high efficiency prospects $[3,4]$, but the present wafer cost may limit its large scale use. The problem is being overcome by growing single crystal indium phosphide films on foreign substrates such as silicon and gallium arsenide $[5,6]$. This approach would provide large area, light weight and mechanically strong cells. The major problems in heteroepitaxy are lattice and thermal expansion mismatch. InP/GaAs cells have shown better results compared to InP/GaAs/Si cells [6]. Weinberg et al. have reviewed the progress in indium phosphide solar cell research at the previous InP conference [7].

The poor heteroepitaxial cell output is caused primarily by the large number of dislocations generated at the interfaces that propagate through the bulk InP layers [8]. This adversely affects the bulk minority carrier properties. The PC10 computer model $[9,10]$ has been used to calculate the cell I-V results and were compared to experimental values measured on $n^{+} / p / p^{+}$indium phosphide on gallium

*This work was done while the author held a National Research Council-NASA LeRC Research Associateship. 
arsenide cells manufactured by Spire Corporation under contract to NASA Lewis. These cells had quite shallow emitter and the size was $0.5 \mathrm{~cm}$ by $0.5 \mathrm{~cm}$. Minority carrier diffusion lengths have been varied to match the measured results on the InP/GaAs cells. A $16 \mathrm{~nm}$ hole diffusion length in the emitter and a $0.42 \mu \mathrm{m}$ electron diffusion length in the base gave quite good agreement with the I-V curve, but the matching with spectral response is not as good. In the present paper our primary purpose has been to estimate the approximate order of the minority carrier diffusion lengths. The effect of varying minority carrier diffusion lengths on cell short circuit current, open circuit voltage and efficiency has been studied. It is also observed that the variation in the front surface recombination velocity has very little influence on the cell performance. Minority carrier diffusion lengths could be improved by controlling the number of dislocations generated using proper buffer layers and growth techniques. AM0 cell efficiency as a function of dislocation density has been calculated and the effect of improvement of emitter bulk properties on cell efficiency is presented. It is found that cells with over 16\% AMO efficiencies should be possible provided the dislocation density is below $10^{6} \mathrm{~cm}^{-2}$. The effect of emitter thickness and doping on cell performance has been described elsewhere [11].

Experimental Indium phosphide heteroepitaxial cells were manufactured by Spire Corporation under contract to NASA Lewis Research Center. Indium phosphide layers were grown using metalorganic chemical vapor deposition (MOCVD) technique on gallium arsenide wafers. Figure 1 shows the $\mathrm{n}^{+} / \mathrm{p} / \mathrm{p}^{+}$solar cell structure. The emitter, base and the buffer layer were $40 \mathrm{~nm}, 3 \mu \mathrm{m}$ and $1 \mu \mathrm{m}$ thick and had doping concentration of $2 \times 10^{18} \mathrm{~cm}^{-3}, 3 \times 10^{16} \mathrm{~cm}^{-3}$ and $1 \times 10^{18} \mathrm{~cm}^{-3}$ respectively. The front and back contacts were made by $\mathrm{Cr} / \mathrm{Au} / \mathrm{Ag}$ and $\mathrm{Au}-\mathrm{Zn}$ alloy respectively. The front grid coverage was $5 \%$ and the cells had a double layer $\mathrm{ZnS} / \mathrm{MgF}_{2}$ antireflection coating. The cell area was $0.25 \mathrm{~cm}^{2}$.

A batch of eight cells was measured at NASA Lewis Research Center under simulated AMO spectrum $\left(137.2 \mathrm{~mW} / \mathrm{cm}^{2}, 25^{\circ} \mathrm{C}\right)$ using a NASA Lear jet calibrated InP standard cell. The average values and standard deviation of the measured short circuit current, open circuit voltage and efficiency (total area) of the eight cells are shown in Table 1.

Results and Discussion The PC-10 computer model developed by Iowa State University $[9,10]$ was used to simulate the experimentally measured cell results. It is important to mention that out of several physical parameters related to InP, which need to be estimated and measured correctly, the exact value of the intrinsic carrier concentration $n_{i}$ is still in doubt. In this work we have used the average value of $n_{j}$ equals to $8 \times 10^{6} \mathrm{~cm}^{-3}$ as suggested in reference 12 . Minority carrier diffusion lengths have been varied to match the calculated values with the experimentally measured results. A $16 \mathrm{~nm}$ hole diffusion length in the emitter and a $0.42 \mu \mathrm{m}$ electron diffusion length in the base gave quite good agreement with the I-V measurements as shown in Table 1 . From the analysis it is clear that the diffusion lengths in the emitter and base of heteroepitaxial cells are quite small. Figures 2 to 5 describe various calculated results and it should be noted that when one parameter is changed all other parameters remain constant.

In Fig. 2 we have plotted the effect of hole diffusion length on the cell performance. It is observed that cell short circuit current and efficiency improves with the increase in diffusion length, while open circuit voltage almost remains same. Improvement in hole diffusion length is essential to achieve 
better cells.

Figure 3 describes the effect of electron diffusion length on cell performance. From this figure it is clear that base minority carrier diffusion length has strong influence on the cell results. Cell short circuit current, open circuit voltage and efficiency improve significantly with increases in diffusion length. Therefore, for achieving high efficiencies, base material quality has to be improved drastically. This in case of heteroepitaxy could be achieved by using better annealing and growth techniques.

Figure 4 plots the effect of front surface recombination velocity (FSRV) on cell efficiency. The FSRV has been varied from $10^{5}$ to $10^{7} \mathrm{~cm} / \mathrm{sec}$. From $\mathrm{Fig}$. 4 we notice a very little improvement in cell efficiency as the FSRV decreases, which is due to slight improvement in the short circuit current as open circuit voltage almost remains constant. Therefore, the FSRV has very little influence on the cell performance, perhaps due to dominant poor bulk properties and the fact that the cells had extremely shallow emitters $(40 \mathrm{~nm})$. It is felt that once the emitter bulk properties are improved, FSRV would certainly play its role in controlling the cell performance.

In Fig. 5 we have plotted the cell AMO efficiency as a function of dislocation density. The dislocation density has been calculated from the simple relation [5] expressed as:

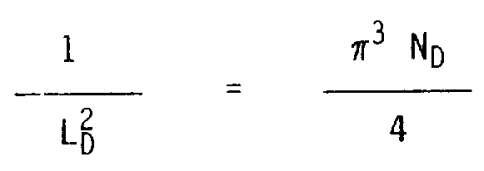

where $L_{D}$ is the dislocation limited minority carrier diffusion length and $N_{0}$ is the dislocation density. The electron diffusion length in the base has been taken as the dislocation limited minority carrier diffusion length. The solid line in Fig. 5 shows the variation of the cell efficiency as a function of dislocation density for a hole diffusion length of $16 \mathrm{~nm}$. It is quite clear that with the decrease in dislocation density, cell efficiency improves almost linearly on a semi-log scale. These results are further improved if the hole diffusion length is improved to $80 \mathrm{~nm}$ as snown by dashed curve. From Fig. 5 it is observed that heteroepitaxial indium phosphide solar cells with over $16 \%$ AM0 efficiencies are possible provided the dislocation density is reached below $10^{6} \mathrm{~cm}^{-2}$. It is hoped that with the advancements in identifying proper buffer layers, suitable annealing and improved growth techniques, it would be possible to manufacture highly efficient, radiation hard, light weight, low cost and mechanically strong heteroepitaxial indium phosphide cells for space power applications.

\section{Conclusions}

Short minority carrier diffusion lengths in the emitter and base are associated for the hetercepitaxial indium phosphide solar cells considered in this work.

Minority carrier diffusion lengths in the emitter and base influence the cell performance, but the base minority carrier diffusion length has a 
significant effect. For improved performance it is required to enhance the base material quality.

Front surface recombination velocity has very little influence on the cell characteristics, perhaps due to poor emitter bulk properties.

Heteroepitaxial indium phosphide cells with over $16 \%$ AMO efficiencies should be possible to fabricate provided dislocation density is below $10^{6} \mathrm{~cm}^{-2}$. This would require improvements in lattice and thermal mismatch and advancements in the development of proper buffer layers and growth techniques.

For understanding fully the physics of indium phosphide solar cells, it is highly essential to determine the various physical parameters of InP and related materials. This study alongwith experimental measurements would be very valuable in pushing the indium phosphide cell technology to meet the increasing power demand of the future space missions.

Acknowledgements Valuable discussions with Dr. I. Weinberg and Mr. D. Wilt if NASA Lewis Research Center, Dr. G. Landis of Sverdrup Technology and Dr. P. A. Basore of Sandia National Laboratories are gratefully acknowledged.

\section{References}

[1] M. Yamaguchi, C. Uemura, A. Yamamoto and A. Shibukawa, 'Electron Irradiation Dallage in Radiation-Resistant InP Solar Cells'.Japan J. Appl. Phys.,23,302307,1984 .

[2] I. Weinberg, C. K. Swartz and R. E. Hart, 'Potential for Use of InP Solar. Cells in the Space Radiation Environment', Proceedings 18th IEEE Photovoltaic Specialists Conference, 21-25,1985.

[3] C. J. Keavney and M. B. Spitzer,'Indium Phosphide Solar Cells by Ion Implantation', App 1. Phys. Letts. 52, 1439-1440, 1988.

[4] H. Okazaki, T. Takamoto, H. Takamura, T. Kamei, M. Ura, A. Yamamoto and M. Yamaguchi,'Production of Indium Phosphide Solar Cells for Space Power Generation', Proceedings 20th IEEE Photovoltaic Specialists Conference, 886$892,1988$.

[5] M. Yamaguchi, A. Yamamoto, N. Uchida and C. Uemura, 'A New Approach for Thin Film InP Solar Cells', Solar Cells, 19,85-96, 1986-1987.

[6] C. J. Keavney, S. M. Vernon, V. E. Haven and S. J. Wojtczuk, 'Fabrication of $n^{+} / p$ InP Solar Cells on Silicon Substrates'. Appl. Phys. Letts.,54,11391141,1989 .

[7] I. Weinberg, D. J. Brinker, C. K. Swartz and R. E. Hart, 'Progress in Indium Phosphide Solar Cell Research', Proceedings First International Conference on Indium Phosphide and Related Materials, 434-444,1989.

[8] S. J. Pearton, K. T. Short, A. T. Macrander, C. R. Abernathy, V. P. Mazzi, N. M. Haegel, M. M. Al-Jassim, S. M. Vernon and V. E. Haven,' Characterization of InP/GaAs/Si Structures Grown by Atmospheric Pressure Metalorganic Chemical Vapor Deposition', J. App 1. Phys.,65, 1083-1088, 1989. 
[9] P. A. Basore, D. T. Rover and A. W. Smith,'PC-1D Version 2: Enhanced Numerical Solar Cell Modeling', Proceedings 20th IEEE Photovoltaic Specialists Conference, 389-396, 1988.

[10] P. A. Basore, PC-1D Installation Manual and User's Guide Version 2.1, Iowa State University Research Foundation, Ames, IA, 1989.

[11] R. K. Jain and D. J. Flood, 'Effect of Emitter Parameter Variation on the Performance of Heteroepitaxial Indium Phosphide Solar Cells', Proceedings 21st IEEE Photovoltaic Specialists Conference, May 1990 (To be published).

[12] A. H. Yahia, M. W. Wanlass and T. J. Coutts, 'Modeling and Simulation of InP Homojunction Solar Cells', Proceedings 20th IEEE Photovoltaic Specialists Conference, 702-707, 1988.

Table 1. Comparison of Measured and Calculated InP Cell Parameters

\begin{tabular}{|l||c|c|c|}
\hline & $\begin{array}{c}\text { Short Circuit Current } \\
(\mathrm{mA})\end{array}$ & $\begin{array}{c}\text { Open Circuit Voltage } \\
(\mathrm{mV})\end{array}$ & $\begin{array}{c}\text { Efficiency } \\
(\%)\end{array}$ \\
\hline $\begin{array}{c}\text { Measured Ave. } \\
\text { (Std. Dev.) }\end{array}$ & $\begin{array}{c}6.654 \\
(0.180)\end{array}$ & $\begin{array}{c}666.6 \\
(0.037)\end{array}$ & $\begin{array}{c}8.92 \\
(0.138)\end{array}$ \\
\hline Calculated & 6.657 & 665.2 & 9.05 \\
\hline
\end{tabular}

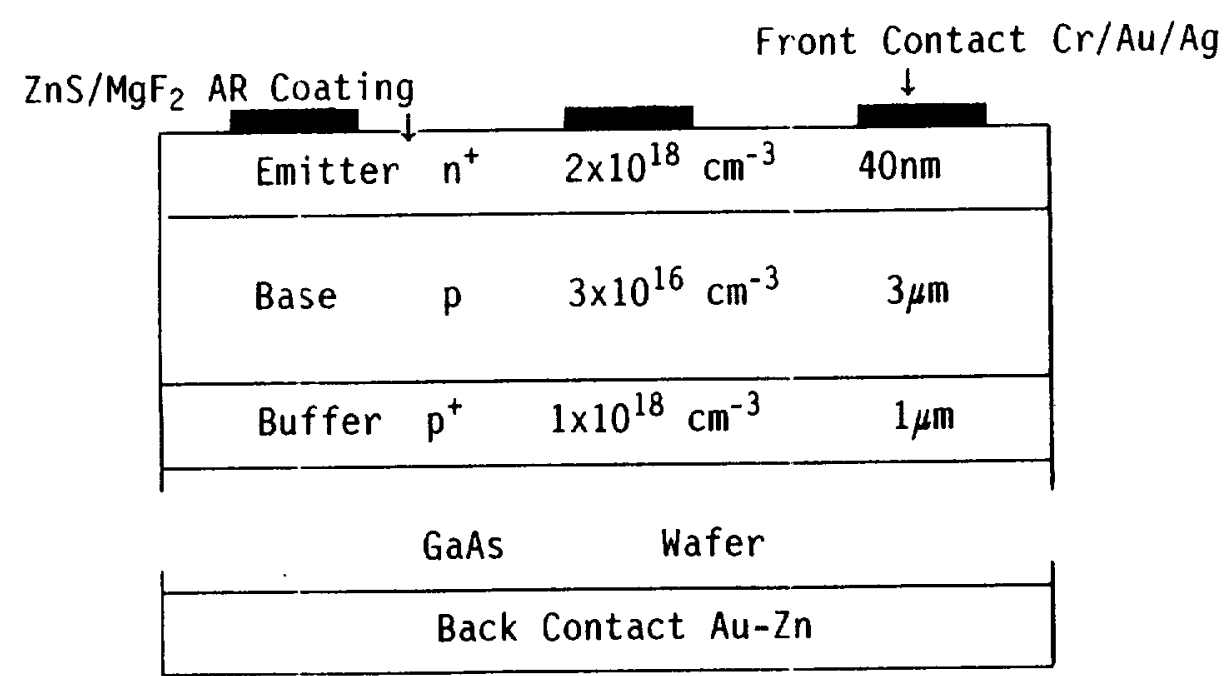

Fig. 1. Structure of a MOCVD Grown InP/GaAs Solar Cell 

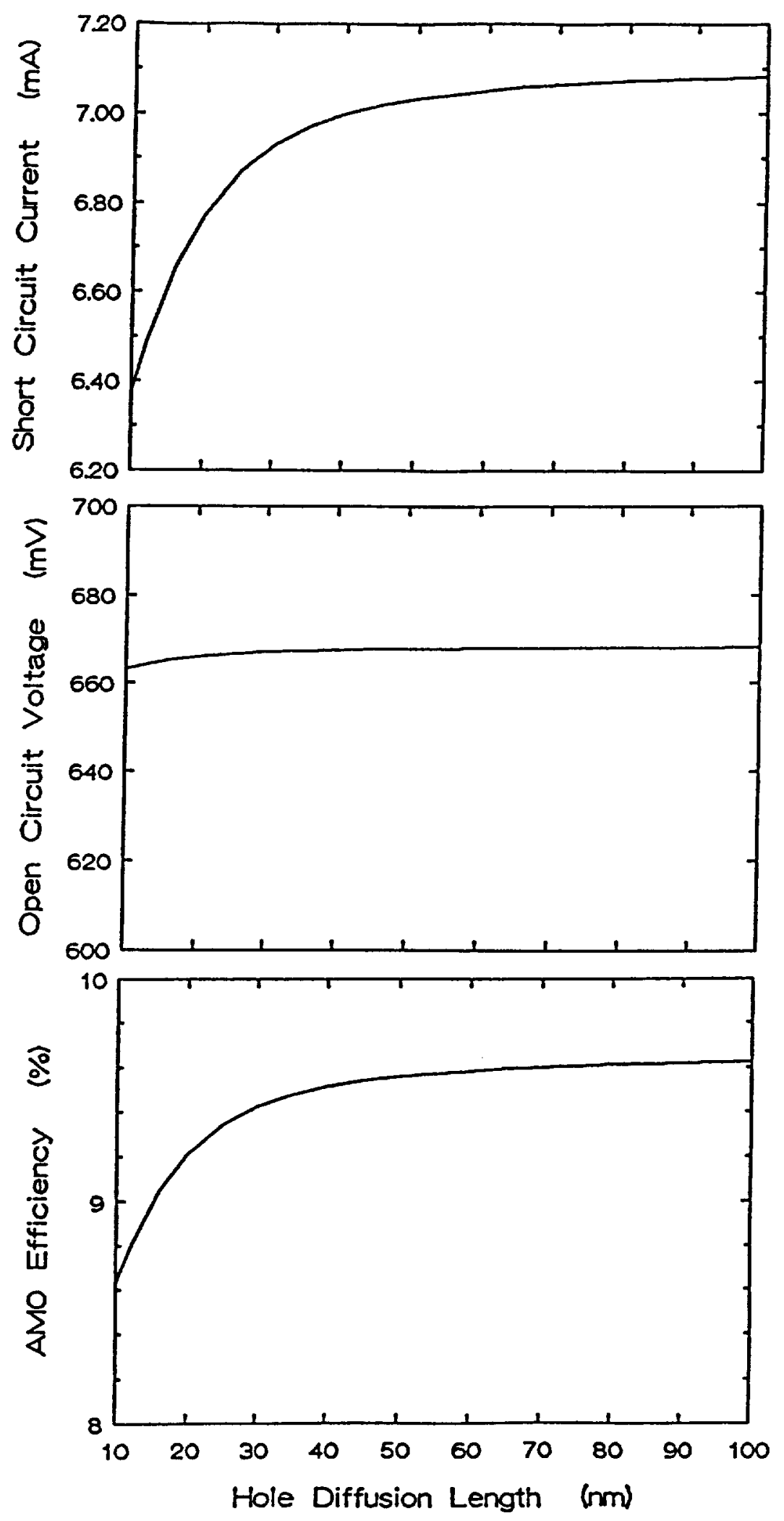

Fig. 2. Effect of Hole Diffusion Length on InP Solar Cell Performance 

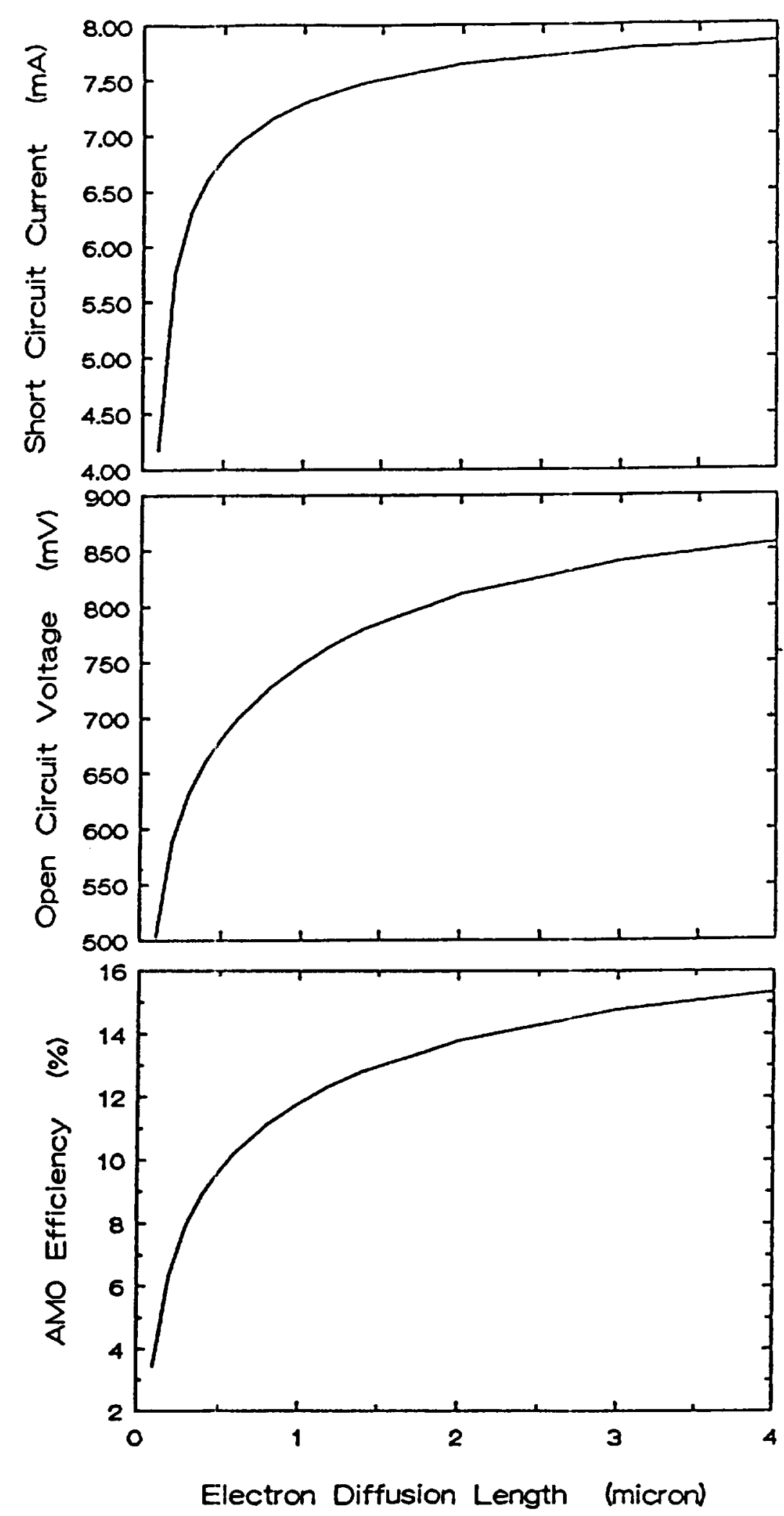

Fig. 3. Effect of Electron Diffusion Length on InP Solar Cell Performance 


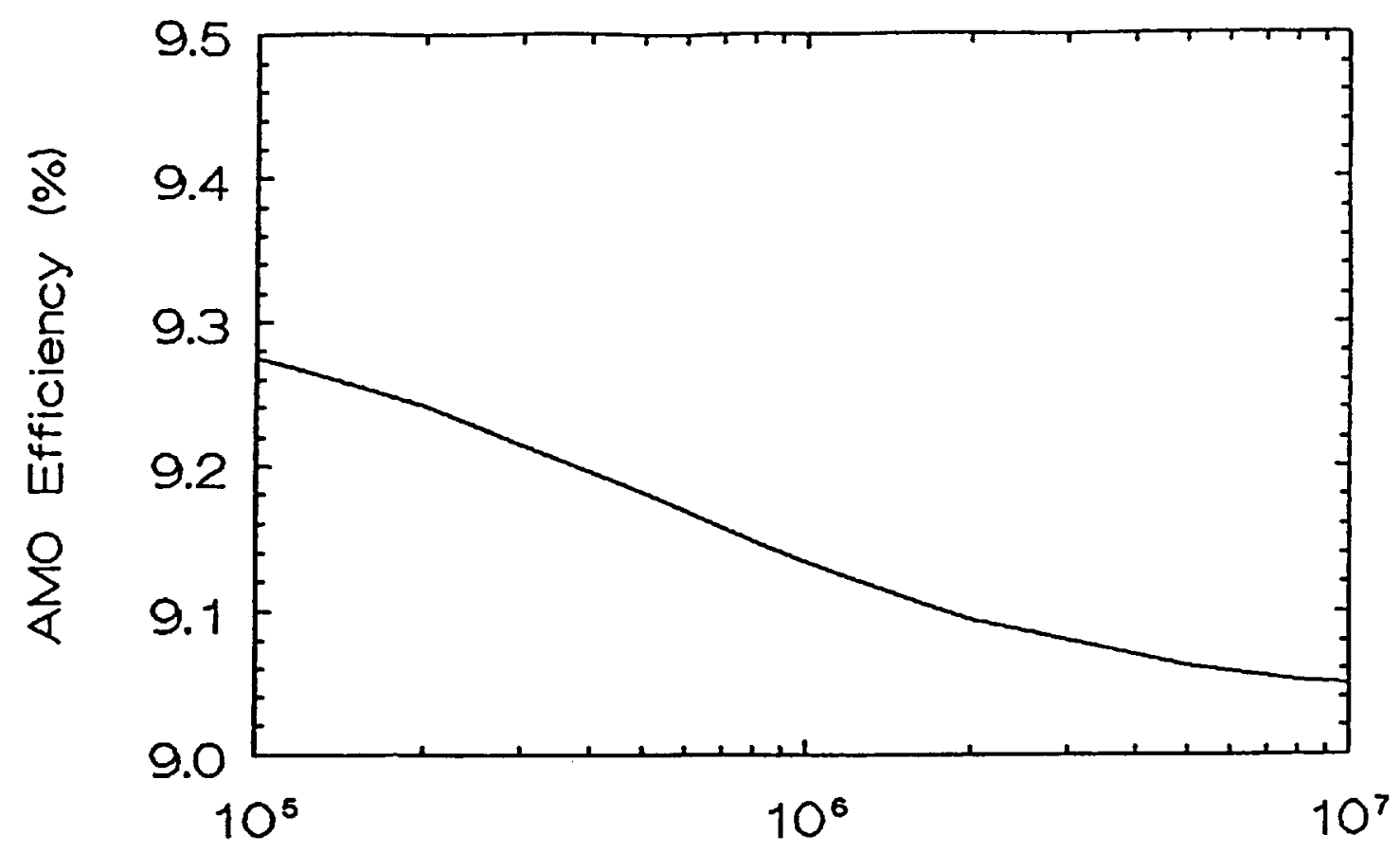

Front Surface Recomb. Velocity $(\mathrm{cm} / \mathrm{sec}\rangle$

Fig. 4. Effect of Front Surface Recombination Velocity on Cell AMo Efficiency

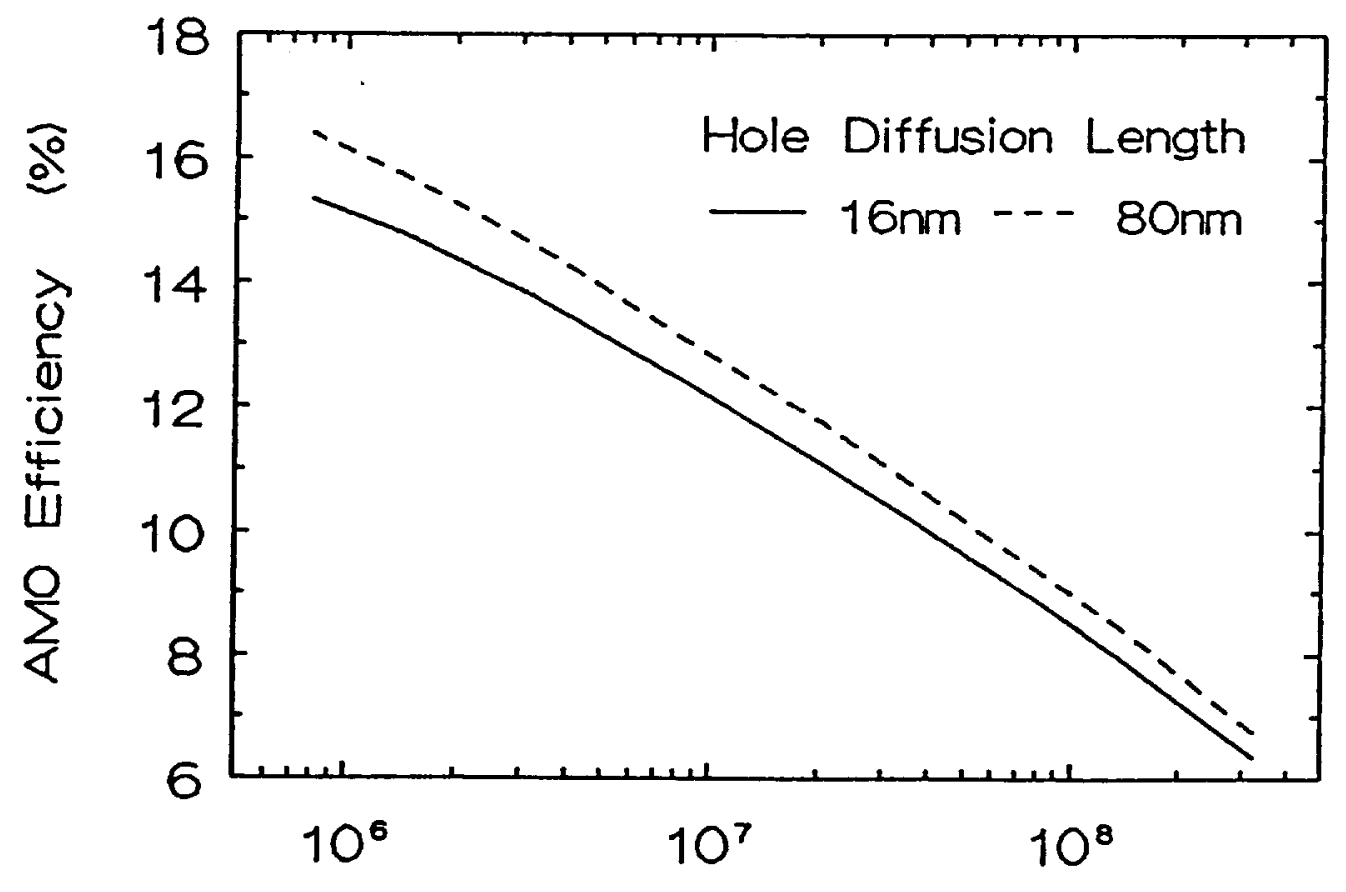

Dislocation Density $(\mathrm{cm}-2)$

Fig. 5. Effect of Dislocation Density on Cell AMO Efficiency 


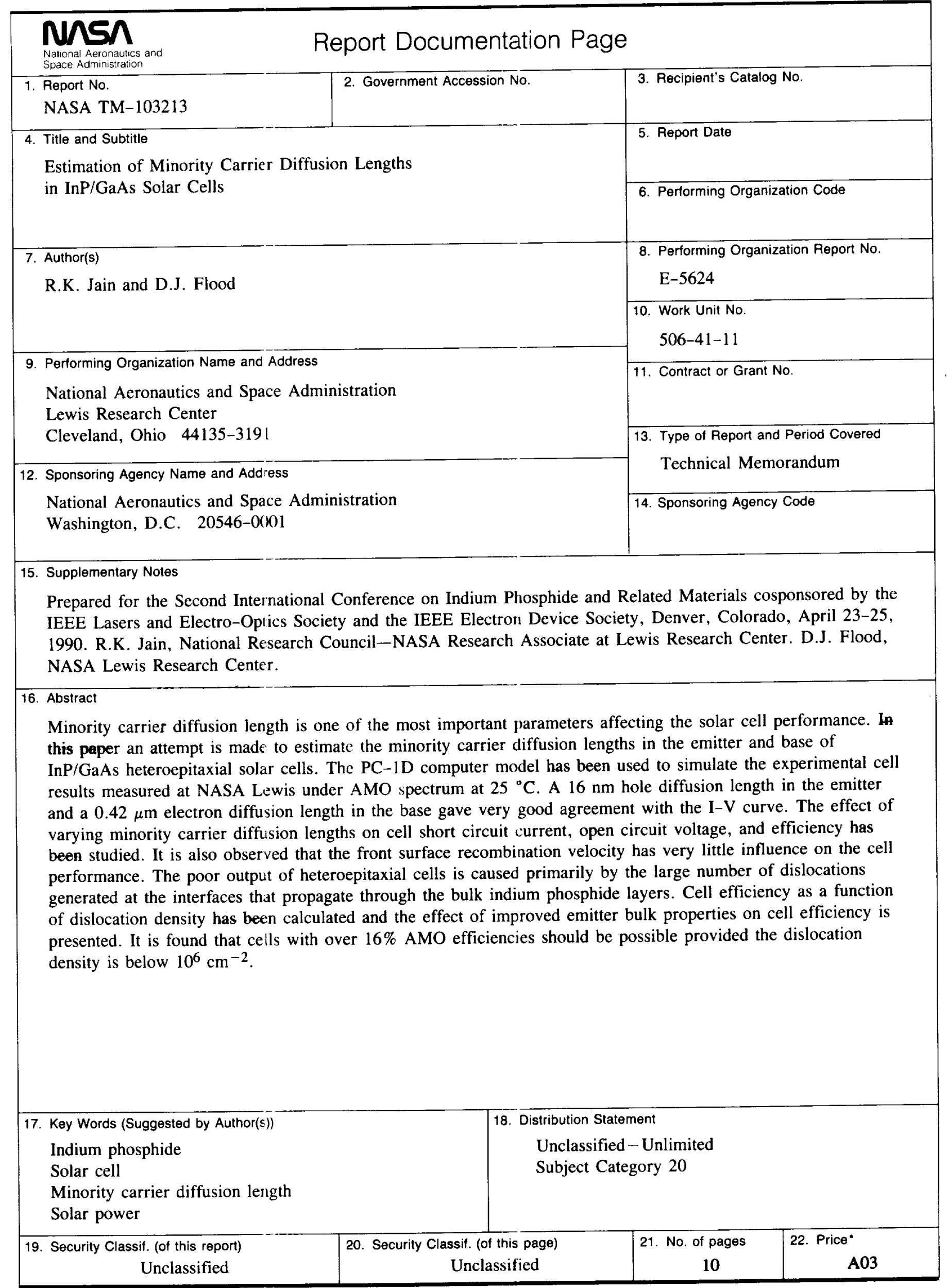


